\title{
Effect of Beta-Adrenergic Agonists on Apnea Reflexes in Newborn Lambs
}

\author{
JENS GROGAARD AND HAKAN SUNDELL ${ }^{(32)}$ \\ Department of Pediatrics Vanderbilt University School of Medicine Nashville, Tennessee, USA and Department of \\ Pediatrics, Centralsjukhuset, 65185 Karlstad, Sweden, [J.G.]
}

\begin{abstract}
Summary
The laryngeal chemoreflex and the trigeminal diving reflex were studied in unanesthetized newborn lambs. Water stimulation of the laryngeal chemoreflex resulted in apnea, bradycardia, hypertension, and blood flow redistribution in the dive pattern. This response was significantly reduced after treatment with beta-adrenergic agonists, e.g., terbutaline. The response to laryngeal saline stimulation was not significantly altered by beta-adrenergic agonists. A similar response to trigeminal dive reflex stimulation elicited through cooling of the snout was also significantly reduced by terbutaline. Propranolol, a beta-adrenergic antagonist, reversed the terbutaline-induced effect on the laryngeal chemoreflex response. Stimulation of the superior laryngeal nerve resulted in a reflex response comparable to that from laryngeal water stimulation. The reflex response was also attenuated by terbutaline, which indicates that the action of terbutaline is not on the laryngeal chemoreceptors. A possible direct effect from beta-adrenergic agonists on the respiratory center is suggested by a latency of 15-30 min before the reflex response was reduced after intravenous but not intrathecal administration. An effect of terbutaline via the arterial chemoreceptors is also possible.
\end{abstract}

\section{Abbreviations}

Ca, carotid artery

Desc Ao, descending thoracic aorta

LCR, laryngeal chemoreflex

NS, normal saline

$\mathrm{Pa}$, main pulmonary artery

SLN, superior laryngeal nerve

TDR, trigeminal diving reflex

Reflex apnea in premature human newborn infants is a frequent occurrence and may be elicited by a number of stimuli. These include suction of the hypopharynx and trachea, (7) cold stimulus to the face, (5) and stimulation of the laryngeal area by water. We $(8,12,20)$ and others $(9,13,14,18,25,27)$ have earlier described the respiratory and cardiovascular responses of the laryngeal chemoreflex (LCR) in newborn animals $(9,12,13,14,18,20,25$, 27). When water is placed on the larynx of newborn lambs, apnea, repeated swallowing, startle, bradycardia, hypertension, and blood flow redistribution in the "dive" pattern occur $(12,13)$. The afferent pathway in this reflex arc travels through the superior laryngeal nerve (SLN), which can be stimulated electrically to produce a response similar to the laryngeal water response $(8,22$, $25,27)$. The trigeminal diving reflex (TDR) can be elicited by a cold stimulus to the trigeminal area of the face in newborn lambs (8). This reflex response consists of apnea accompanied by a multiorgan response similar to the diving reflex response in diving mammals $(1,2,4,17)$. The previous study of the laryngeal chemoreflex showed that the cardiovascular response correlates with the magnitude of the respiratory response. Pharmacologic beta-adrenergic blockade with propranolol resulted in a more pronounced cardiovascular response (12).

The purpose of this study was to delineate the effect of a betaadrenergic agonist, terbutaline on LCR and TDR responses in unanesthetized newborn lambs. Beta-adrenergic agonists, such as terbutaline, are frequently used in obstetrics in an attempt to stop premature labor. These drugs are known to be bronchodilators and to increase respiratory and heart rate (11). The effects on the fetus and the newborn infant are, however, still essentially unknown.

\section{MATERIALS AND METHODS}

Eleven healthy, normally grown lambs of Dorset or Suffolk breeds were studied. The lambs were instrumented with a tracheostomy and catheters for pressure readings on the second or third day of life after being fed with mothers' milk for at least $24 \mathrm{~h}$ postpartum. Four of the lambs were, in addition, also equipped with electromagnetic perivascular flow cuffs ( $\mathrm{C}$ and $\mathrm{C}$ Instruments, Inc, Culver City, CA) placed around the left carotid artery $(\mathrm{Ca})$, the main pulmonary artery $(\mathrm{Pa})$ and the descending thoracic aorta (Desc Ao). After recovery from the surgical procedures, most lambs were able to return to their mothers. The remainder were fed ewe's milk or milk replacer (Land O'Lakes Inc, Fort Dodge, IA) by automatic nipple feeding. The tracheostomy was plugged by a curved silver tracheostomy tube with a proximal opening allowing the lamb to breathe through the nose.

During the study, the tracheostomy tube was replaced by a downward directed, tight fitting endotracheal tube (Portex, 4-6). The pneumotachograph was interposed between the tube and a $B A B Y$ bird respirator, which supplied continuous humidified air flow and continuous positive airway pressure of $+2 \mathrm{~cm} \mathrm{H}_{2} \mathrm{O}$ to compensate for a decreased functional residual capacity due to endotracheal intubation. A biluminal balloon catheter (French 8 Foley) was directed upward in the tracheostoma with the tip placed below the larynx, and the balloon was inflated closely to the proximal trachea. Water and saline solutions could, therefore, be flushed retrograde through the larynx without compromising ventilation. Statham transducers $(\mathrm{P} 23 \mathrm{G}$ b) were used for pressure measurements. All the tracings were made with an 8 channel Hewlett Packard $8800 \mathrm{~S}$ cardiovascular recording system. ECG and the integrated heart rate based on $\mathrm{R}$ wave triggering were recorded. The pneumotachograph was connected to a respiratory integrator. Blood flows were measured with electromagnetic blood flow meters (Narcomatic, Model RT 510 Narco Bio-Systems, Inc., Houston, TX). The clinical state of the lamb was continuously monitored through the experimental period with frequent blood gas analysis, (Instrumentation Laboratory, Model 213, Watertown, MA). Rectal temperature was kept at $39 \pm 0.5^{\circ} \mathrm{C}$ and the ambient temperature at $23^{\circ} \mathrm{C}$. Hyperthermia in the lamb was treated by cooling with ice packs. The lambs were studied unanesthetized, awake, and unrestrained in their customary cages. The preparations were kept between 8-38 days. The weights of the lambs during the study were $4.1-10.7 \mathrm{~kg}$. After death, the larynx was 
inspected with light microscopy to assure that the epithelium still was intact.

Experimental protocol. LCR response to water and normal saline was tested in a standardized manner. Distilled water was used for stimulation and as the solvent for the normal saline (NS) solution $(0.15 \mathrm{M} \mathrm{NaCl})$. Solutions were kept in a warm water bath at the lamb's body temperature of $39^{\circ} \mathrm{C}$. Each test consisted of a baseline period of $25 \mathrm{sec}$ followed by injection of $15 \mathrm{ml}$ of the test solution retrograde on to the larynx through the balloon catheter during a $25-\mathrm{sec}$ period. Ten seconds later, the catheter was flushed with normal saline. The lambs were allowed to recover between each test. Respiratory volume, blood pressure, heart rate, and blood gases were monitored in order to indicate that the lamb had returned to the original baseline state $\left(\mathrm{PaO}_{2}\right.$ higher than 60 torr and $\mathrm{PCO}_{2} 30-40$ torr) before the next test was performed. A series of four stimulations was made with water, alternating with a series of four stimulations with normal saline. Testing of the TDR response was thereafter carried out four times by using a wet, ice cold towel gently held against the lamb's snout for $25 \mathrm{sec}$. The LCR response was tested in all the lambs. The TDR response was tested in six lambs, three of which were instrumented with flowcuffs.

Reflex responses were tested during $1-2 \mathrm{~h}$ before and after terbutaline administration. Terbutaline was given as an initial i.v. push of $50-200 \mu \mathrm{g} / \mathrm{kg}$. Lambs that did not respond to the initial dose of $50 \mu \mathrm{g} / \mathrm{kg}$ terbutaline were given an additional infusion mixed in D5W: $60-120 \mu \mathrm{g} / \mathrm{kg} / \mathrm{h}$ i.v. over a $1-4-\mathrm{h}$ period. Seven of the lambs were given a total dose of $240 \mu \mathrm{g} / \mathrm{kg}$. In order to register the effects of high terbutaline doses, four lambs were given additional i.v. pushes and these lambs received a total dose of $0.6-2$ $\mathrm{mg} / \mathrm{kg}$. Five lambs were given propranolol $1 \mathrm{mg} / \mathrm{kg}$ i.v. push, after the terbutaline effect was observed, in order to compare the LCR response before and after beta-adrenergic blockade.

Superior laryngeal nerve stimulation. Three of the lambs were anesthetized with chloralose, and the right superior laryngeal nerve was dissected and cut close to the larynx. The reflex could now be initiated in two ways, either in the way previously described by injecting water into the larynx, the reflex passing via the intact left SLN, or by direct electrical stimulation of the divided right nerve (SD5 Stimulator, Grass Medical Instruments, Quincy, MA). The electrical stimulation remained constant throughout the studies and was achieved with 2 volts, $0.5 \mathrm{msec}$ duration and a frequency of 10 pulses per sec. SLN stimulations were performed before and after terbutaline administration i.v. $(25 \mu \mathrm{g} / \mathrm{kg})$ or intrathecally $(13,25$ and increasing doses up to 150 $\mu \mathrm{g} / \mathrm{kg}$, respectively).

Other beta-adrenergic agonists were also tested in order to show that the effect from terbutaline was related to its beta-adrenergic activity. Fenoterol hydrobromide, $100 \mu \mathrm{g} / \mathrm{kg}$ i.v. push, followed by a continuous infusion of $10 \mu \mathrm{g} / \mathrm{kg}$ fenoterol i.v. was given to one lamb. After a series of reflex tests, metoprolol, a relatively selective beta-1-adrenergic blocker, was given, $4 \mathrm{mg} / \mathrm{kg}$ over a 10-20-min period. Salbutamol, a beta-adrenergic agonist, and metoprolol were given to the same lamb in the same manner and in the same doses at another occasion. Isoproteronol, a betaadrenergic agonist, was given in increasing doses to a total of 90 $\mu \mathrm{g} / \mathrm{kg}$ to one lamb.

Data analysis. The reflex response was expressed as \% change from baseline values for respiration (ventilation volume), heart rate, systemic blood pressure, systemic vascular resistance, and blood flows. After the initial apnea response, the lambs started to breathe during the last half of the TDR stimulation period. Analysis of the response to TDR stimulation was, therefore, performed during the first $10 \mathrm{sec}$. Respiration (ventilation volume) was measured as the volume of gas inspired during the baseline or stimulation periods, during $25 \mathrm{sec}$ for the LCR and during $10 \mathrm{sec}$ for the TDR. Blood pressure, heart rate and flows were measured at $20 \mathrm{sec}$ for LCR and at $10 \mathrm{sec}$ for TDR after onset of stimulation. Data is presented as mean \pm S.E. The paired $t$ test was used in statistical analysis to assess significance; $P<0.05$ was considered as a significant change.

\section{RESULTS}

Respiratory and cardiovascular responses to TDR and LCR stimulation in the unanesthetized lamb consisted of immediate apnea, bradycardia, hypertension, and blood flow redistribution with a decreased flow in the descending aorta and an increased or unchanged flow in the carotid artery. Cardiac output decreased proportionate to the fall in heart rate. Figure $1 \mathrm{a}$ and $\mathrm{b}$ illustrate the LCR response obtained before and after terbutaline administration in a 12-day-old lamb. Table 1 presents baseline values for respiratory rate, heart rate, blood pressure and blood flows, stroke volume, and systemic vascular resistance obtained before the individual LCR tests performed before and after medication with terbutaline. Respiratory rate, heart rate and blood flows in $\mathrm{Pa}$ and Desc Ao increased significantly, whereas systemic vascular resistance decreased significantly after terbutaline administration.

Respiratory response to TDR and LCR stimulation with water was significantly reduced after terbutaline in nine of the eleven animals (Fig. 2). One set of twin lambs showed no significant change in respiratory response after terbutaline. The LCR response to saline was not altered by terbutaline. The onset of the drug effect was gradual during the first 15-30 min after the initial bolus dose was given.

Heart rate. The heart rate response (bradycardia) to LCR water and TDR stimulation was significantly decreased by terbutaline (Fig. 3) in eight of the 11 lambs. Two lambs, which both had significantly altered respiratory response, had no changes in heart rate response. One lamb had a slight but not significant increase in heart rate response. The LCR response to saline was not significantly altered by terbutaline.

Blood pressure. The systolic and diastolic hypertensive response seen with laryngeal water and TDR stimulation was significantly attenuated by terbutaline in 10 out of 11 lambs. The pressure response to LCR saline stimulation was not significantly changed (Fig. 4).

Blood flow. Blood flow measurements were performed in the four lambs equipped with flow cuffs. These lambs had a marked effect of terbutaline (respiratory response to LCR water stimulation decreased from $87 \pm 3$ to $29 \pm 16$ ). As seen in Figure 5 there was also a significant decrease in the cardiac output response to LCR water and TDR stimulation after terbutaline in these lambs. After terbutaline medication, redistribution of bloodflow proportionate to the total response was still seen during LCR water stimulation.

Systemic vascular resistance. Figure 6 shows that the pronounced increase in vascular resistance in response to both LCR water and TDR stimulation is markedly reduced by terbutaline in the four lambs with flow cuffs.

Superior laryngeal nerve stimulation. Electrical stimulation of the divided SLN in three lambs resulted in a response similar to LCR water stimulation (Fig. 7). The respiratory and cardiovascular responses were blocked in one lamb after $25 \mu \mathrm{g} / \mathrm{kg}$ terbutaline i.v. Terbutaline $13 \mu \mathrm{g} / \mathrm{kg}$ given intrathecally to a second lamb also blocked the response to SLN-stimulation within $5 \mathrm{~min}$. A third lamb had only a modest reduction of the LCR water response by terbutaline when studied unanesthetized. This lamb required $150 \mu \mathrm{g} / \mathrm{kg}$ terbutaline intrathecally to reduce the respiratory response to $60 \%$.

Reversal of terbutaline effect on $L C R$ with propranolol. Figure 8 illustrates that propranolol given i.v. significantly reversed $(P<$ $0.005)$ the attenuating effect of terbutaline on the respiratory response to LCR water stimulation in five lambs. Heart rate and blood pressure responses to LCR stimulation also increased after propranolol, although not significantly.

Other beta-adrenergic agonists and metoprolol. Fenoterol and salbutamol were found to have an equal effect as terbutaline on the LCR response in one lamb in which the response to water was reduced by one half. Metroprolol, a relatively selective beta-1adrenergic blocker, did not alter the LCR response already attenuated by fenoterol or salbutamol. Isoproterenol (isoprenaline) given to one lamb caused weakness, doubling of heart rate and 

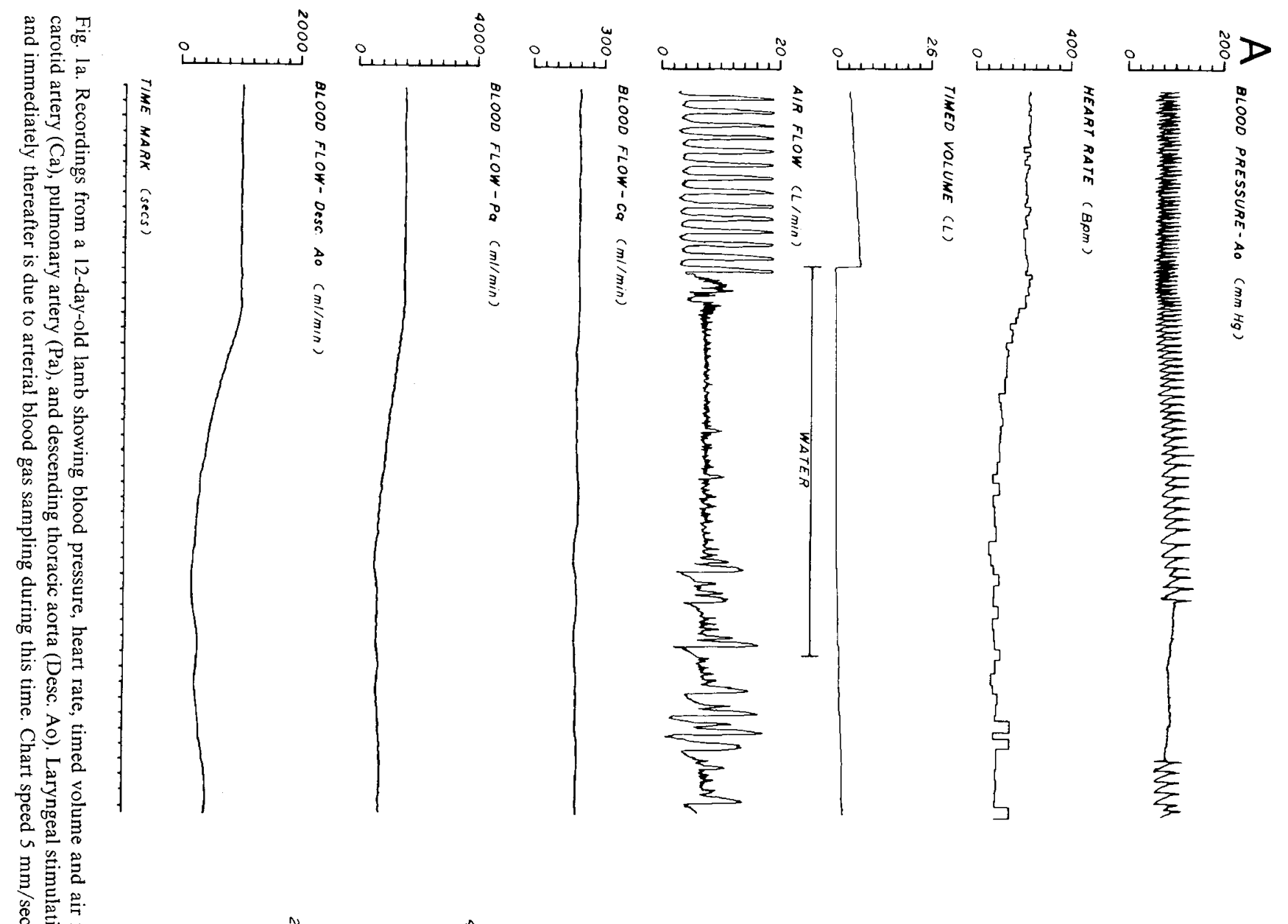

更

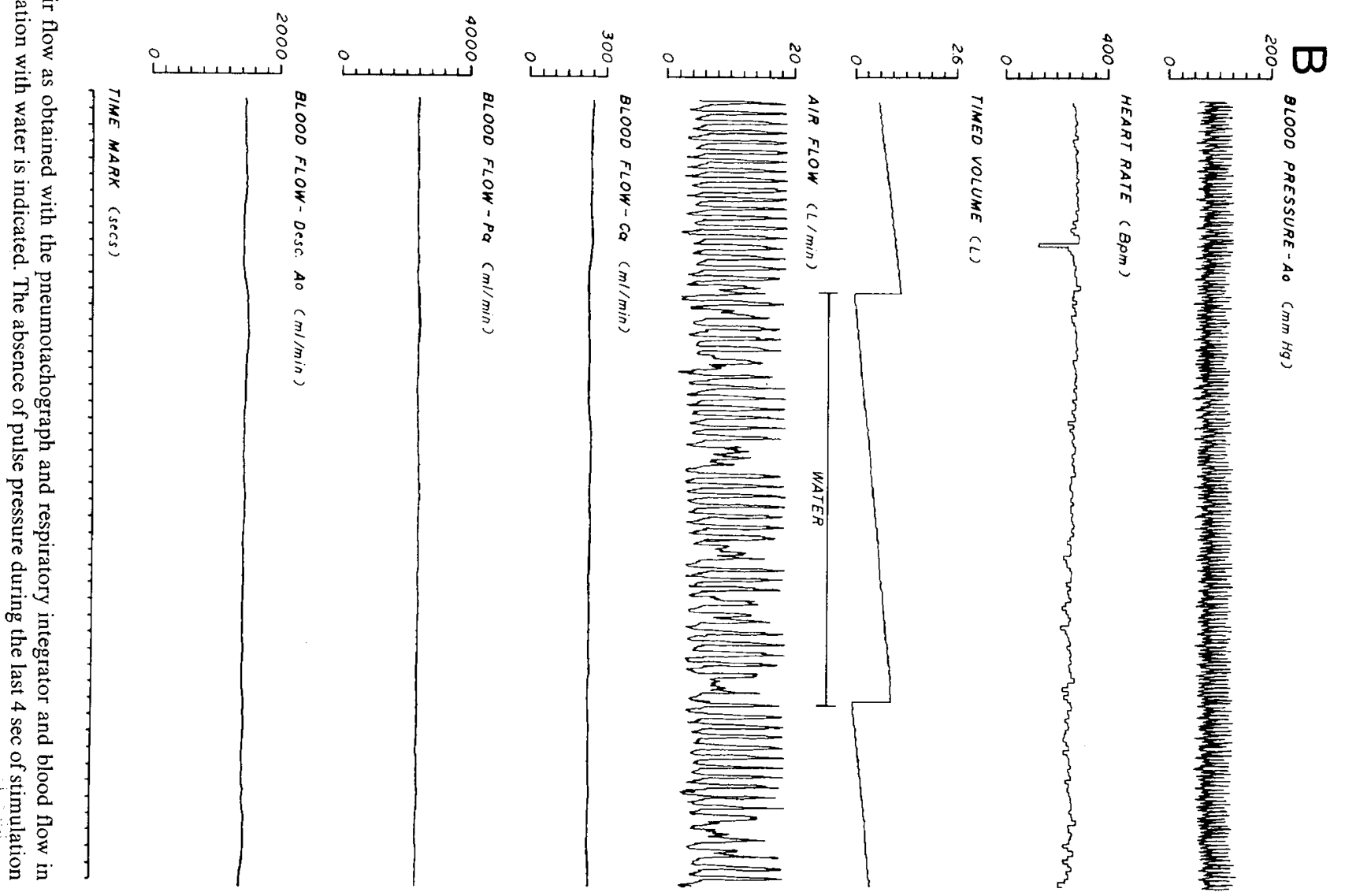


Table 1. Effect of terbutaline on baseline variables (mean $\pm S . E.)^{1}$

\begin{tabular}{|c|c|c|c|c|}
\hline & $n$ & $\begin{array}{c}\text { Before } \\
\text { terbutaline }\end{array}$ & $\begin{array}{c}\text { After } \\
\text { terbutaline }\end{array}$ & $P$ \\
\hline Respiratory rate (bpm) & 11 & $66 \pm 10$ & $88 \pm 9$ & $<0.005$ \\
\hline Heart rate $(\mathrm{bpm})$ & 11 & $195 \pm 9$ & $262 \pm 9$ & $<0.001$ \\
\hline $\begin{array}{l}\text { Systolic blood pressure } \\
\text { (torr) }\end{array}$ & 11 & $110 \pm 4$ & $106 \pm 6$ & $\mathrm{NS}^{2}$ \\
\hline $\begin{array}{l}\text { Diastolic blood pressure } \\
\text { (torr) }\end{array}$ & 11 & $65 \pm 3$ & $59 \pm 3$ & NS \\
\hline $\begin{array}{l}\text { Blood flow:pulmonary ar- } \\
\text { tery }(\mathrm{ml} / \mathrm{min})\end{array}$ & 4 & $1527 \pm 142$ & $2178 \pm 270$ & $<0.025$ \\
\hline $\begin{array}{l}\text { Blood flow:descending } \\
\text { thoracic aorta }(\mathrm{ml} / \mathrm{min})\end{array}$ & 4 & $1005 \pm 52$ & $1420 \pm 112$ & $<0.01$ \\
\hline $\begin{array}{l}\text { Blood flow:left carotid ar- } \\
\text { tery }(\mathrm{ml} / \mathrm{min})\end{array}$ & 4 & $178 \pm 10$ & $210 \pm 41$ & NS \\
\hline Stroke volume $(\mathrm{ml})$ & 4 & $8.2 \pm 1.3$ & $8.7 \pm 1.3$ & NS \\
\hline $\begin{array}{l}\text { Systemic vascular resist- } \\
\text { ance (torr } \times \mathrm{min} / \text { liter) }\end{array}$ & 4 & $55 \pm 5$ & $38 \pm 5$ & $<0.001$ \\
\hline
\end{tabular}

${ }^{1}$ The averages of eight determinations in each lamb performed immediately before laryngeal chemoreflex stimulations were used for these calculations.

${ }^{2} \mathrm{NS}$, not significant.

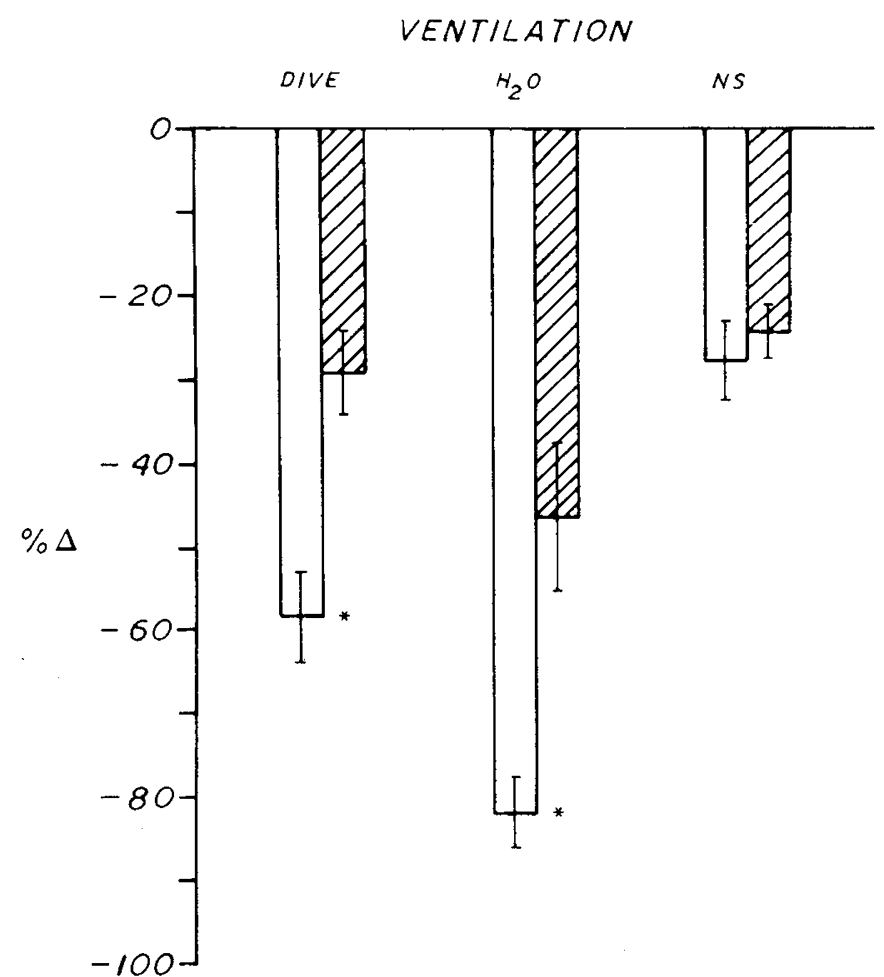

Fig. 2. Respiratory response to trigeminal diving reflex and laryngeal chemoreflex water $\left(\mathrm{H}_{2} \mathrm{O}\right)$ and saline (NS) stimulation in 6 and 11 lambs, respectively (mean \pm S.E.) Open bars indicate response before terbutaline. Cross hatched bars indicate response after terbutaline. $\left({ }^{*}\right)$ Indicates significant difference between responses obtained before and after terbutaline.

respiratory rate. After a total dose of $90 \mu \mathrm{g} / \mathrm{kg}$ only a moderate attenuating effect on the laryngeal water response was seen.

\section{DISCUSSION}

This study shows that the respiratory and cardiovascular responses obtained after stimulation of the laryngeal chemo- and trigeminal diving reflexes can be attenuated by terbutaline, a betaadrenergic agonist. Other observed effects of terbutaline include an increase in respiratory and heart rates and a decrease in

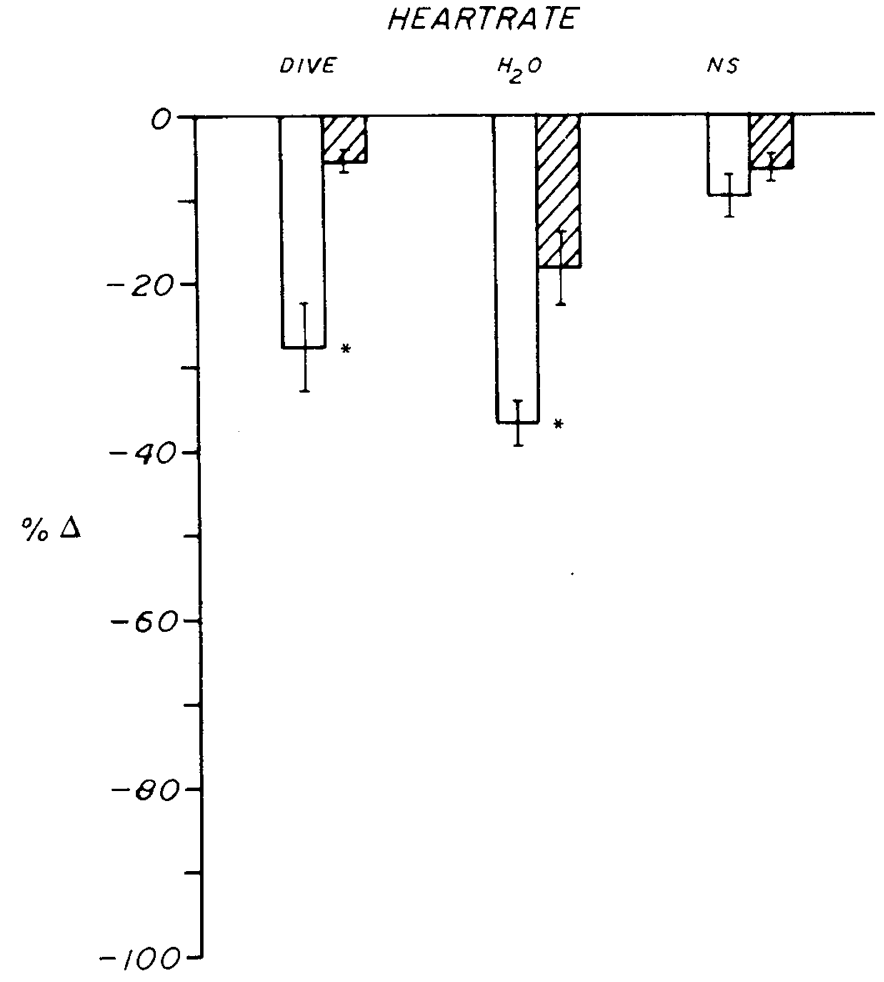

Fig. 3. Heart rate response to trigeminal diving reflex and laryngeal chemoreflex water $\left(\mathrm{H}_{2} \mathrm{O}\right)$ and saline (NS) stimulation in 6 and 11 lambs, respectively (mean $\pm \mathrm{S}$.E.). Open bars indicate response before terbutaline. Cross hatched bars indicate response after terbutaline. $\left({ }^{*}\right)$ Indicates significant difference between responses obtained before and after terbutaline.

systemic vascular resistance. Previous investigators have reported hyperpnea associated with infusion of beta-adrenergic agonists, such as isoproterenol $(10,15,19,21,30)$. An increase in heart rate and cardiac output, and a decrease in systemic vascular resistance has been observed following terbutaline medication (6).

Reversal with propranolol of the terbutaline effect on LCR response to water stimulation indicates that the terbutaline effect on the reflex response is due to a beta-adrenergic agonist effect. The effect is not limited to terbutaline because other beta-adrenergic agents also had a similar effect on these reflexes. Terbutaline is said to act primarily on beta-2-receptors (11). Metoprolol, a relatively selective beta-1-adrenergic blocker, did not change the response in a lamb treated with two other relatively selective beta2 -agonists (fenoterol and salbutamol). The beta-adrenergic effect on LCR, therefore, appears to be due to beta-2-stimulation.

An opposite effect on the LCR response is seen after betaadrenergic blockade. We have previously reported that propranolol significantly increased the fall in cardiac output and the raise in systemic vascular resistance resulting from LCR water stimulation (12).

Several possible mechanisms exist through which terbutaline might exert its effect on these apnea reflexes. An increase in the sensitivity of the arterial chemoreceptors to hypoxemia, an increase in the central respiratory drive or a direct effect on the laryngeal chemoreceptors are possibilities to consider.

Wasserman, et al. (28) have postulated that hyperpnea induced by isoproterenol was caused by an increase in cardiac output, and that the mechanism might be due to a precise regulation of $\mathrm{PaCO}_{2}$ by rapidly responding respiratory chemoreceptors. In a later publication (29) they showed that the peripheral arterial chemoreceptors and possibly vagal afferents play a major role in the hyperpnea caused by isoproterenol. Eldridge et al. (10) and Llados and Zapata (24) have demonstrated that the major and most immediate respiratory effect of isoproterenol is related to its action on the 
SYSTOLIC BP RESPONSE

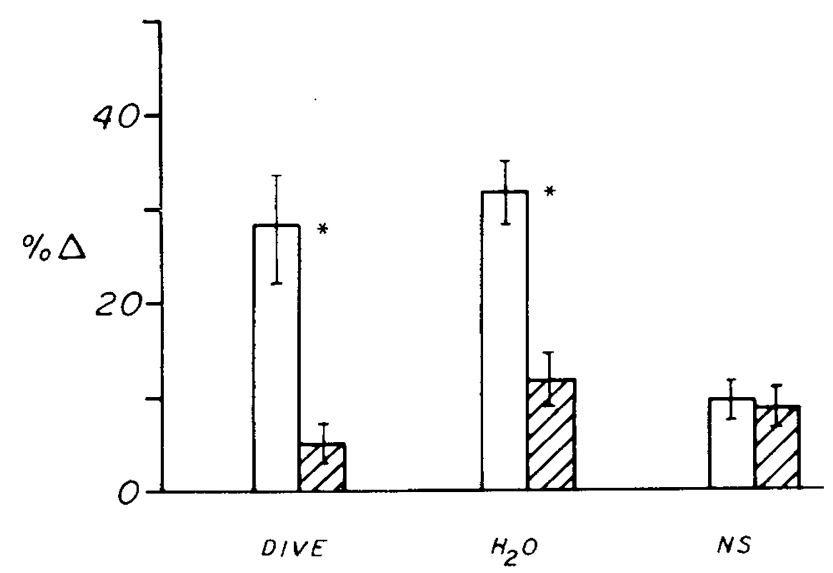

DIASTOLIC BP RESPONSE

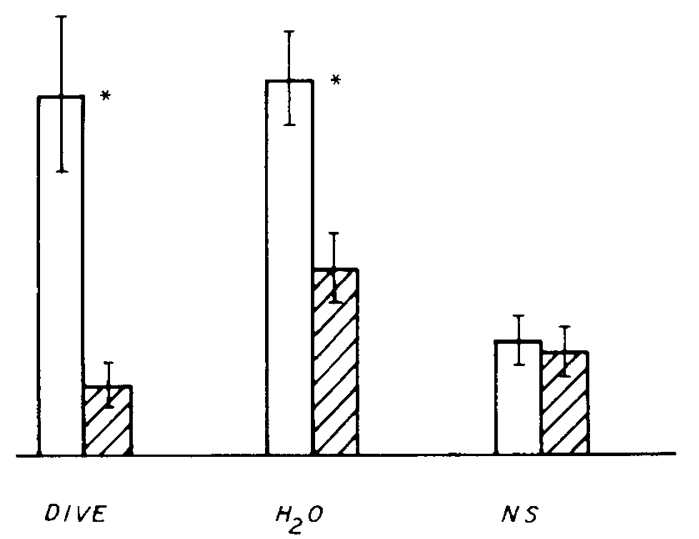

Fig. 4. Blood pressure response to trigeminal diving reflex and laryngeal chemoreflex water $\left(\mathrm{H}_{2} \mathrm{O}\right)$ and saline (NS) stimulation in 6 and 11 lambs, respectively (mean \pm S.E.). Open bars indicate response before terbutaline. Cross hatched bars indicate response after terbutaline. $\left({ }^{*}\right)$ Indicates significant difference between responses obtained before and after terbutaline.

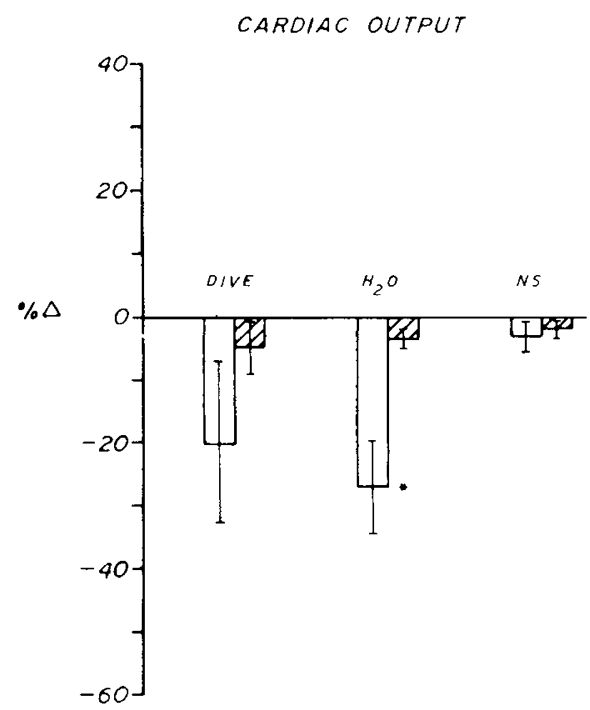

CAROTID FLOW

AORTIC FLOW
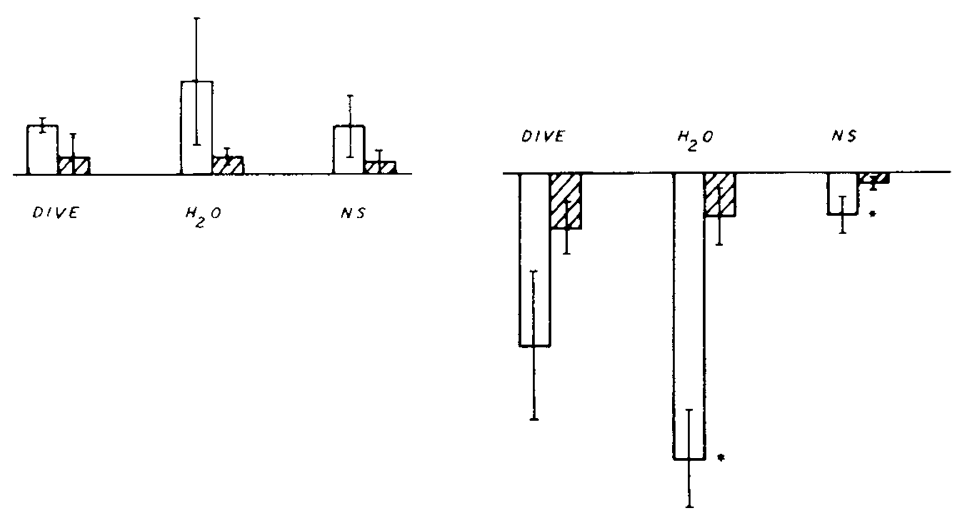

Fig. 5. Blood flow redistribution response to trigeminal diving reflex and laryngeal chemoreflex and saline (NS) stimulation in 3 and 4 lambs, respectively (mean \pm S.E.). Open bars indicate response before terbutaline. Cross hatched bars indicate response after terbutaline. $\left({ }^{*}\right)$ Indicates significant difference between responses obtained before and after terbutaline.

carotid bodies, which leads to increased output by the respiratory center. Because isoproterenol and terbutaline both are beta-adrenergic agonists, the postulated effect through the carotid bodies on respiration might also apply to terbutaline. Angell-James and Daly (3) have shown that in the presence of a pronounced inhibitory effect on respiration, such as stimulation from facial or laryngeal receptors, an input to the nervous system from the carotid bodies was usually ineffective in stimulating respiration. If the major effect of terbutaline is a direct stimulating action on the carotid bodies, the response of the carotid bodies to concomitant hypoxemia might no longer be overridden by the LCR stimulation, and the LCR apnea response would, therefore, decrease.

The onset of the terbutaline effect on the LCR and TDR response appeared gradually over 15-30 min whereas the effect from intrathecal injections was instantaneous, indicating a possible direct effect on the respiratory center. A beta-adrenergic action on the respiratory center has also been described by others. In their studies of the mechanism of hyperpnea by isoproterenol, Eldridge, et al. (10) found, beside the excitatory action on the carotid body, another small late facilatating effect probably related to the central nervous system. Millhorn et al. (26) continued these studies in the cat and demonstrated a new pontomedullary neural mechanism, activated by peripheral chemoreceptor afferent input, but, once activated this mechanism sustains respiration at an increased level for a long period of time. They postulated that this effect could be due to the release of a long acting central neurotransmitter or modulator and suggested that this central transmitter is serotonin.

Terbutaline equally affected the response to laryngeal water stimulation and to electrical stimulation of the superior laryngeal nerve, indicating that the action of terbutaline is not local on the receptors in the laryngeal epithelium. A local effect on the chemoreceptors in the laryngeal epithelium has, however, recently been demonstrated for bupivacaine given i.v. (8).

There was a marked variance in the effect of terbutaline on the response to LCR and TDR stimulation, which did not appear to be directly dose related. Lambs given higher doses than $40-200$ $\mu \mathrm{g} / \mathrm{kg}$ did not show a more pronounced effect on the reflex responses. Compared to clinically used terbutaline doses in humans and studies in animals (6), the lambs ought to have received sufficient amounts of the drug for full pharmacologic effect. All the lambs developed an increased respiratory rate and cardiovascular signs comparable to a terbutaline effect.

The observation that some of the lambs showed less effect on the LCR response with high doses $1-2 \mathrm{mg} / \mathrm{kg}$ may indicate that 
SYSTEMIC VASCULAR RESISTANCE

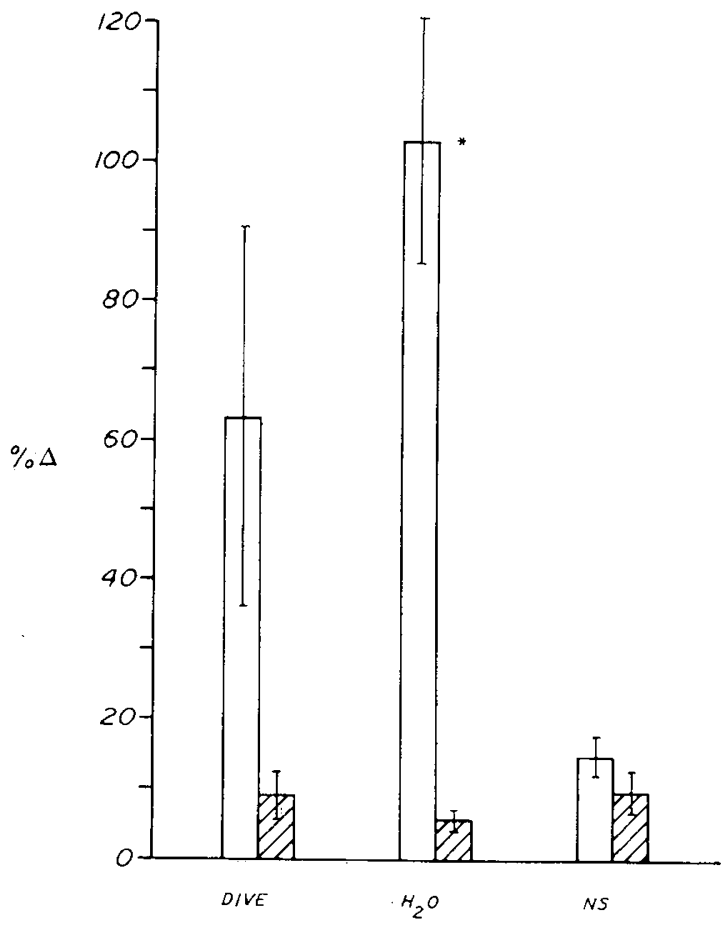

Fig. 6. Systemic vascular resistance response to trigeminal diving reflex and laryngeal chemoreflex water $\left(\mathrm{H}_{2} \mathrm{O}\right)$ and saline (NS) stimulation in 3 and 4 lambs, respectively (mean \pm S.E.). Open bars indicate response before terbutaline. Cross hatched bars indicate response after terbutaline ${ }^{*}$ ) Indicates significant difference between responses obtained before and after terbutaline.

\section{VENTILATION}

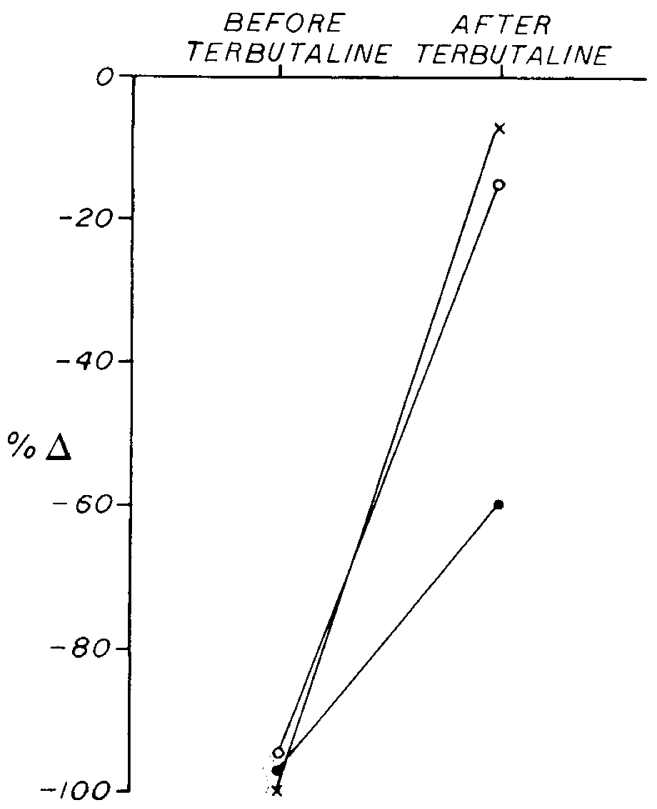

Fig. 7. Effect of terbutaline on the respiratory response to superior laryngeal nerve stimulation in three anesthetized lambs.

there is an upper therapeutic level in the effect of terbutaline on the apnea reflexes. Another explanation for the variable response in the present study might be related to desensitization of the receptors with very high doses of terbutaline $(23,31)$.

The results in the present study may have clinical implications. Beta-adrenergic agonists are presently the drugs of choice for the
VENTILATION

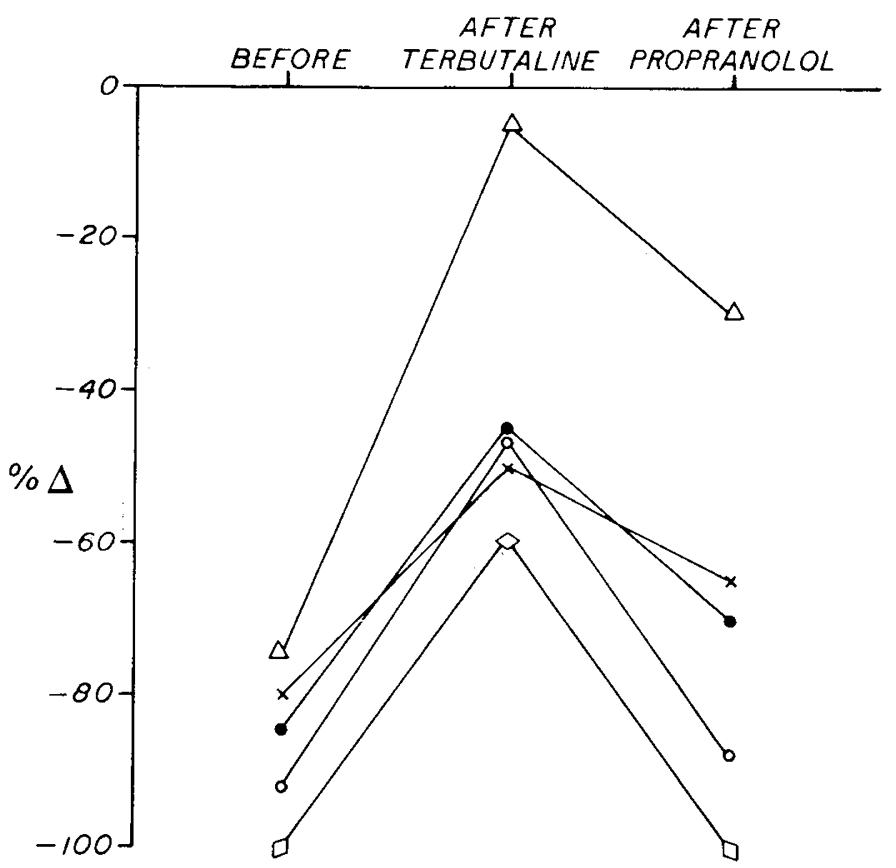

Fig. 8. Propranolol reversal of terbutaline effect on laryngeal chemoreflex respiratory response to water stimulation in five newborn lambs.

attempted suppression of premature labor. Antepartum heart rate testing is the primary method of predicting fetal well-being. Fetal heart rate variability, fetal heart rate accelerations or decelerations with fetal movements and fetal heart rate decelerations with uterine contractions are the most reliable components of heart rate testing (16). If beta-adrenergic agonists are transferred from the mother to the fetus in a sufficient amount and affect fetal reflex responses in a way similar to that shown in these newborn lambs, then fetal heart rate patterns would no longer be accurate reflectors of fetal well-being. Furthermore, newborn infants, especially prematures, whose mothers received beta-adrenergic agonists may have altered reflex response to stimuli during their resuscitation and in the first critical hours of extra-uterine life. The use of betaadrenergic agents for suppression of reflex apnea, elicited in other ways than by laryngeal chemo stimulation, might, however, be therapeutically advantageous and deserves further evaluation.

\section{REFERENCES AND NOTES}

1. Andersen, H. T: Cardiovascular adaptations in diving mammals. Am. Heart $\mathbf{J}$, 74: 295 (1967).

2. Andersen, H. T. and Blix, A. S.: Pharmacological exposure of components in the automatic control of the diving reflex. Acta Physiol. Scand., 90: 381 (1974).

3. Angell-James, J. E. and Daly, M de B.: The interaction of reflexes elicited by stimulation of carotid body chemoreceptors and receptors in the nasal mucosa affecting respiration and pulse interval in the dog. J. of Physiol., 229: 133 (1973).

4. Blix, A. S., Goutvik, E. L., and Refsun, H.: Aspects of the relative roles of peripheral vasoconstriction and vagal bradycardia in the establishment of the "diving reflex" in ducks. Acta Physiol. Scand., 90: 289 (1974).

5. Brown, W. U., Ostheimer, G. W., Bell, G. C., and Datta, S. S.: Newborn response to oxygen blown over the face. Anesthesiology, 44: 535 (1976).

6. Burnell, R. H. and Maxwell, G. M.: The cardiovascular effects of terbutaline. Europ. J. of Pharmacol., 15: 383 (1971)

7. Cordero, L. Jr. and Hon, E. H.: Neonatal bradycardia following nasopharyngeal stimulation. J. Pediatr., 78: 441 (1971).

8. Corke, B. C., Sundell, H., and Marchal, F.: The blocking effect of bupivacaine on the laryngeal chemo and the trigeminal diving reflex in the newborn lambs. Pediatr. Pharmacol., 2: 105 (1982).

9. Downing, S. E. and Lee, J. C.: Laryngeal chemosensitivity: a possible mechanism for Sudden Infant Death. Pediatrics, 55: 640 (1975).

10. Eldridge, F. L. and Gill-Kumar, P.: Mechanisms of hyperpnea induced by isoproterenol. Respir. Physiol., 40: 349 (1980).

11. Goodman, L. S. and Gilman, A.: The pharmacological basis of therapeutics. p. 477 (MacMillan Publishing, New York, New York 1975).

12. Grogaard, J., Sundell, H., and Stahlman, M. T.: The cardiovascular response to laryngeal water administration in young lambs. J. Develop. Physiol., (In Press). 
13. Harding, R., Johnson, P., Johnston, B. E., McClellan, M. F., and Wilkinson, A. R.: Cardiovascular changes in newborn lambs during apnea induced by stimulation of the laryngeal receptors with water. J. Physiol., 256: 35P (1975)

14. Harned, H. S., Myracle, J., and Ferrerio, J.: Respiratory suppression and swallowing from introduction of fluids into the laryngeal region of the lamb. Pediatr. Res., 12: 1003 (1978).

15. Heistad, D. D., Wheeler, R. C., Mark, A. L., Schmid, P. G., and Abboud, F. M. Effects of adrenergic stimulation on ventilation in man. The J. of Clin. Invest. 51: 1469 (1972).

16. Hon, Edward H.: An introduction to fetal heart rate monitoring. 2nd ed., Dept. of Ob. \& Gyn., U. of Southern Cal. School of Medicine, Los Angeles, California (1975)

17. Huxley, F. M.: On the reflex nature of apnea in the duck in diving: $[-$ The reflex nature of submersion apnea. Quart. J. Exp. Physiol., 6: 147 (1913).

18. Johnson, P., Salisbury, D. M., and Storey, A. T.: Apnea induced by stimulation of sensory receptors in the larynx. Bosma, and Showacre, Eds: Developmen of Upper Respiratory Anatomy and Function. DHEW publication (NIH) 75941, p. 160.

19. Keltz, H., Samortin, T., and Stone, D. J.: Hyperventilation: a manifestation of exogenous $\beta$-adrenergic stimulation. Amer. Rev. Resp. Dis., 105: 637 (1972).

20. Kovar, I., Selstam, U., Catterton, W. Z., Stahlman, M. T., and Sundell, H. W.: Laryngeal chemoreflex in newborn lambs: Respiratory and swallowing response to salts, acids and sugars. Pediatr. Res., 13: 1144 (1979).

21. Krasnow, N., Rolett, E. L., Yurchak, P. M., Hood, W. B., Jr., and Gorlin, R. Isoproterenal and cardiovascular performance. Amer. J. Med., 37: 514 (1964)

22. Lawson, E. E.: Prolonged central respiratory inhibition following reflex-induced apnea. J. Appl. Physiol.: Respirat. Environ. Exercise Physiol., 50: 874 (1981).

23. Lefkowitz, R. J.: Mini Review, The beta-adrenergic receptor. Life Sci., 18: 461 (1976).

24. Llados, F. and Zapata, P.: Effects of adrenoceptor stimulating and blocking agents on carotid body chemosensory inhibition. J. Physiol., 274: 501 (1978).
25. Lucier, G. E., Storey, A. T., and Sessle, B. J.: Effects of upper respiratory tract stimuli on neonatal respiration: Reflex and single neuron analyses in the kitten. Biol. Neonate, 35: 82 (1979).

26. Millhorn, D. E., Eldridge, F. L., and Waldrop, T. G.: Prolonged stimulation of respiration by a new central neural mechanism. Respir. Physiol., 41: 87 (1980).

27. Sutton, D., Taylor, E. M., and Lindeman, R. C.: Prolonged apnea in infant monkeys resulting from stimulation of superior laryngeal nerve. Pediatrics, 61 : 519 (1978).

28. Wasserman, K., Whipp, B. J., and Castagna J.: Cardiodynamic hyperpnea: hyperpnea secondary to cardiac output increase. J. Appl. Physiol., 36: 457 (1974).

29. Wasserman, K., Mitchell, R. A., Berger, A. J., Casaburi, R., and Davis, J. A.: Mechanism of the isoproterenol hyperpnea in the cat. Resp. Phys., 38: 359 (1979).

30. Winn, R., Hildebrandt, J. R., and Hildebrandt, J.: Cardiorespiratory responses following isoproterenol injection in rabbits. J. Appl. Physiol.: Respirat. Environ. Exercise Physiol., 47: 352 (1979).

31. Yamaguchi, I. Torda, T., Hirata, F and Kopin, I. J.: Adrenoceptor desensitization after immobilization stress or repeated injection of isoproterenol. Am. J. Physiol., 240: H69l (1981).

32. Requests for reprints should be addressed to: Dr. Hakan Sundell, Dept. of Pediatrics, Vanderbilt University, School of Medicine, Nashville, TN 37232.

33. This research was supported by grants from the National Institute of Child Health and Human Development (No. HD10454) and March of Dimes Birth Defects Foundation (No. 1-739).

34. The authors thank Dr. Mildred $\Upsilon$. Stahlman for her support and advice and Patricia Minton, R.N., Rao Gaddipati, Linda Jones and Stanley Poole, Research Assistants, for their skilled and helpful assistance.

35. Received for publication January $20,1982$.

36. Accepted for publication June 16, 1982 